\title{
Electrically conductive epoxy nanocomposites containing carbonaceous fillers and in-situ generated silver nanoparticles
}

\author{
A. Dorigato $^{1 *}$, G. Giusti $^{1}$, F. Bondioli $^{2}$, A. Pegoretti $^{1}$ \\ ${ }^{1}$ University of Trento, Department of Industrial Engineering and INSTM Research Unit, Via Mesiano 77, 38123 Trento, Italy \\ ${ }^{2}$ University of Modena and Reggio Emilia, Department of Engineering 'Enzo Ferrari', Via Vignolese 905, 41125 Modena, \\ Italy
}

Received 25 February 2013; accepted in revised form 21 April 2013

\begin{abstract}
An epoxy resin was nanomodified with in-situ generated silver nanoparticles (Ag) and with various amounts of carbon black $(\mathrm{CB})$ and carbon nanofibers $(\mathrm{NF})$, in order to increase the electrical conductivity of the matrix. Differential scanning calorimetry tests revealed how the addition of both CB and NF led to a slight decrease of the glass transition temperature of the material, while electron microscopy evidenced how the dimension of $\mathrm{CB}$ aggregates increased with the filler content. Both flexural modulus and stress at yield were decreased by CB addition, and the introduction of Ag nanoparticles promoted an interesting improvement of the flexural resistance. CB resulted to be more effective than NF in decreasing the electrical resistance of the materials down to $10^{3} \Omega \cdot \mathrm{cm}$. Therefore, a rapid heating of the CB-filled samples upon voltage application was observed, while Ag nanoparticles allowed a stabilization of the temperature for elevated voltage application times.
\end{abstract}

Keywords: nanocomposites, epoxy, nanoparticles, nanofibers

\section{Introduction}

Due to their low density and good adhesive and mechanical properties, epoxy resins are among the most widespread matrices for structural composites. Because of their chemical versatility and the possibility to tailor the glass transition temperature by using different epoxy bases and/or chain extenders, they were often applied in several technological applications [1]. Furthermore, it has been widely proven that the addition of metal and carbon based nanofillers, such as metal nanopowders, graphite nanoplatelets ( $\mathrm{GnPs})$, carbon black (CB) and carbon nanofibers (NFs) could dramatically improve the mechanical behavior and the electrical conductivity of the resulting materials [2-4]. The electrical behav- ior of these systems can be successfully explained considering the percolation theory [5]. Above a given filler content (i.e. the percolation threshold), the conductive particles form a continuous network through the insulating matrix and the resistivity is harshly decreased by several orders of magnitude. For instance, in a recent work of our group, the thermomechanical properties and the electrical monitoring capability under ramp and creep conditions of an epoxy matrix nanomodified with different amounts of CB and NF was investigated [6]. The best formulation was then used to prepare glass fiber reinforced laminates to be tested under ramp and creep conditions, with a continuous monitoring of their deformational and damage behavior through electrical measurements [7].

\footnotetext{
${ }^{*}$ Corresponding author, e-mail: andrea.dorigato@ing.unitn.it (C) BME-PT
} 
Recently, different kinds of polymeric materials have been utilized for the preparation of shape memory materials (SMMs). These materials have the peculiar property of 'remembering' their original shape to which they return when subjected to external stimuli $[8,9]$. Among them, shape memory alloys (SMAs) and shape memory polymers (SMPs) are the most important ones at present, and their efficacy is strictly connected to their final application [10]. They have been widely applied as smart textiles and apparels [11], intelligent medical devices [12], heat shrinkable packages for electronics [13], high performance water-vapor permeability materials [14], self-deployable structures [15], and microsystems [16]. SMPs can recover their original (or permanent) shapes under appropriate external stimuli, such as heating $[1,8,16,17]$, cooling [18], light $[19,20]$, electric field [21-26], magnetic field [2729], water [30], pH, specific ions or enzyme [31]. However, the demand to avoid external heaters has led to a new generation of electrically conducting SMPs filled with conductive nanoparticles, such as carbon nanotubes [21, 22], carbon particles [23, 26], conductive fiber [24] and nickel zinc ferrite ferromagnetic particles.

Taking into account these considerations, the objective of the present work is to characterize the thermal, mechanical and electrical properties of new epoxy based nanocomposites whose amine hardener was nanomodified with in-situ reduced silver nanoparticles. Moreover, various amounts of carbon based nanofillers (CB and NF) were dispersed in the polymer matrix in order to evaluate possible synergistic effects. This paper represents the first step of a wider characterization activity focused on the selection of the most promising filler compositions for the preparation of nanofilled polymers with electrically induced shape memory behavior.

\section{Experimental}

\subsection{Materials}

A DER 330 epoxy base (density $=1.16 \mathrm{~g} / \mathrm{mL}$, epoxy equivalent $=176-185 \mathrm{~g} / \mathrm{eq}$ ), supplied by Dow Chemical Company (Midland, USA), and a Jeffamine D400 amine hardener (molecular weight $=430 \mathrm{Da}$, density $=0.972 \mathrm{~g} / \mathrm{mL}$, amine equivalent $=115 \mathrm{~g} / \mathrm{eq}$ ), supplied by Huntsman (Everberg, Belgium), were utilized as components of the epoxy system. The same hardener, modified with silver nanoparticles (Ag), was obtained through the in-situ reduction of silver nitrate $\left(\mathrm{AgNO}_{3}\right.$, Sigma Aldrich) [32]. Typically, the reaction solutions were prepared by dissolving $13.3 \mathrm{~g}$ of $\mathrm{AgNO}_{3}$ in $100 \mathrm{~g}$ of hardener kept at $55^{\circ} \mathrm{C}$. After 6 hours, the obtained suspension is characterized by a strong UV visible absorption band at $410 \mathrm{~nm}$ characteristic of $\mathrm{Ag}^{0}$ (here not reported). The shape and the dimensions of the particles were also evaluated by TEM. The obtained images showed that the synthesized powder was nanostructured and presented crystals having rather uniform spherical shape and size in the range from 2 to $5 \mathrm{~nm}$ (Figure 1). Thermogravimetric tests evidenced how the nanomodified hardener was characterized by an $\mathrm{Ag}$ content of $8.6 \mathrm{wt} \%$.

Ketjenblack EC600JD carbon black (CB) was supplied by Akzo Nobel Chemicals Spa (Arese, Italy). This nanofiller is constituted by fine aggregates of spherical particles with typical dimension of around $40 \mathrm{~nm}$. The specific surface area (SSA) of CB nanoparticles, measured following BET procedure, was $1353 \mathrm{~m}^{2} / \mathrm{g}$, while the density assessed by helium pycnometry was about $1.95 \mathrm{~g} / \mathrm{cm}^{3}$. Vapour grown carbon nanofibers $(1195 \mathrm{JN})$ have been supplied by NanoAmor Inc. (Houston, USA). According to the product data sheet, these fibres have a length of $5-$ $40 \mu \mathrm{m}$, a core diameter of $0.5-10 \mathrm{~nm}$ and an outside diameter of $240-500 \mathrm{~nm}$. The SSA values of NF resulted to be $29 \mathrm{~m}^{2} / \mathrm{g}$, while a density of $1.78 \mathrm{~g} / \mathrm{cm}^{3}$ was evaluated. All materials were used as received. As far as the preparation of the samples is concerned, different amounts of CB and NF were manually mixed with the epoxy base for 5 minutes. The mixture was then ultrasonicated by using a Hielscher

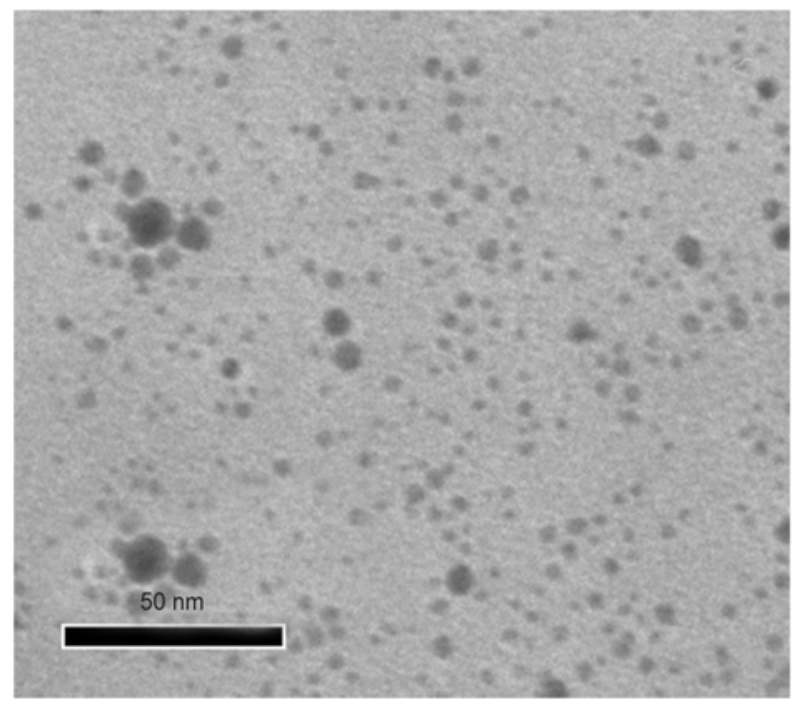

Figure 1. TEM image of the amine hardener with Ag nanoparticles 
sonicator for 10 minutes applying a specific power of $100 \mathrm{~W} / \mathrm{m}^{2}$. The stoichiometric amount of hardener was then added to the mixture and manually mixed for 5 minutes. In the case of neat epoxy, a base/hardener ratio of 100/63.9 was utilized, while for the Ag nanomodified epoxy the presence of silver nanoparticles within the hardener led to a stoichiometric ratio of $100 / 70$. After the degassing process, the compounded materials were poured in silicone molds and cured for $2 \mathrm{~h}$ at $40^{\circ} \mathrm{C}+3 \mathrm{~h}$ at $110^{\circ} \mathrm{C}+2 \mathrm{~h}$ at $130^{\circ} \mathrm{C}$. In this way, neat epoxy and relative nanocomposites with $\mathrm{CB}$ or NF amounts between 1 and $4 \mathrm{wt} \%$ were prepared. In order to evaluate the effect of the silver nanoparticles within the epoxy matrix, the same samples were prepared by using the Ag nanomodified matrix. In the Results and discussion section, neat epoxy and the Ag nanomodified matrix were designated as $\mathrm{EP}$ and $\mathrm{EP}+\mathrm{Ag}$, respectively. Nanofilled samples were denoted indicating the nanofiller amount, the nanofiller type and the presence (or not) of Ag nanoparticles within the matrix. For instance, $1 \mathrm{CB}$ refers to the nanocomposite sample with a $\mathrm{CB}$ amount of $1 \mathrm{wt} \%$, while $1 \mathrm{CB}+$ $\mathrm{Ag}$ indicates the same nanocomposite prepared by using the Ag nanomodified epoxy.

\subsection{Experimental techniques}

Morphology of the cryofractured surfaces of the nanofilled samples was investigated by a Zeiss Supra 40 field emission scanning electronic microscope (FESEM), at an acceleration voltage of about $1 \mathrm{kV}$ and a pressure of $10^{-6}$ Torr. The surfaces of the samples were metalized with a silver paste before the observations. The glass transition temperature $\left(T_{\mathrm{g}}\right)$ was evaluated by differential scanning calorimetry (DSC) tests, performed with a Mettler DSC30 apparatus (Schwerzenbach, Switzerland). A thermal cycle from -20 to $160^{\circ} \mathrm{C}$, at a heating rate of $10^{\circ} \mathrm{C} \cdot \mathrm{min}^{-1}$ under a nitrogen flow of $100 \mathrm{~mL} \cdot \mathrm{min}^{-1}$, was adopted. Flexural tests for the determination of elastic modulus $(E)$ and flexural stress at yield $\left(\sigma_{\mathrm{y}, \mathrm{f}}\right)$ were performed at $23^{\circ} \mathrm{C}$ and at relative humidity of $50 \%$ according to ASTM 790-10 standard by using an Instron ${ }^{\circledR} 4502$ testing machine (Norwood, Massachusetts, USA). Rectangular samples, $2 \mathrm{~mm}$ thick and $5 \mathrm{~mm}$ wide, were tested setting a distance between the supports of $40 \mathrm{~mm}$ and a testing speed of $1.33 \mathrm{~mm} / \mathrm{min}$ (maximum strain rate of $0.01 \mathrm{~min}^{-1}$ ). At least five specimens were tested for each sample. Electrical bulk resistance measurements were per- formed at $23{ }^{\circ} \mathrm{C}$ and at relative humidity of $50 \%$ in direct current mode. A model 6517A 6 1/2-digit electrometer/high resistance system, by Keithley Instruments Inc. (Cleveland, Ohio, USA) was used for electrical measurement in a 2-point test configuration. In order to decrease the contact resistance, the sample surfaces in contact with the electrodes were painted with a silver coating. Measurements were carried out on rectangular samples (cross section of $5 \mathrm{~mm} \times 2 \mathrm{~mm}$, length of $30 \mathrm{~mm}$ ), and at least five specimens were tested for each composition. When the electrical resistance was lower than $10^{5} \Omega$, measurements were carried out under an applied voltage of $10 \mathrm{~V}$, and the resistance values were measured after a time lapse of $60 \mathrm{~s}$, in order to minimize timedependent effects. When the electrical resistance was between $10^{5}$ and $10^{12} \Omega$, measurements were carried out under an applied voltage of $100 \mathrm{~V}$. When the electrical resistance was higher than $10^{12} \Omega$, measurements with an applied voltage of $1000 \mathrm{~V}$ were taken on square film samples (length of $95 \mathrm{~mm}$ and thickness of $2 \mathrm{~mm}$ ). In this latter case coaxial electrodes were used in order to minimize the amount of current flowing through the surface. In order to evaluate the Joule effect produced by the current flowing through the samples upon voltage application, surface temperature measurements were performed. The same equipment and configuration used for electrical resistivity measurements was adopted, and various voltages ranging from 100 to $220 \mathrm{~V}$ were applied. The increase of the temperature produced by the electrical heating of the samples was monitored through an Optris ${ }^{\circledR}$ LaserSight infrared digital thermometer, acquiring an experimental point every $30 \mathrm{~s}$.

\section{Results and discussion 3.1. Microstructure}

It is well known that the thermal and the mechanical behavior of nanocomposite samples is directly influenced by the dispersion state of the nanofiller within the matrix. In Figure 2a-2h) FESEM images of the fracture surfaces of the prepared nanocomposites are reported. As it is often claimed in the scientific literature $[6,7]$, the microstructure of $\mathrm{CB}$ nanocomposite system is characterized by the presence of primary particles arranged in aggregates and agglomerates, homogeneously distributed within the polymer matrix. 1CB system is characterized by the presence of tiny and pale primary particles with 


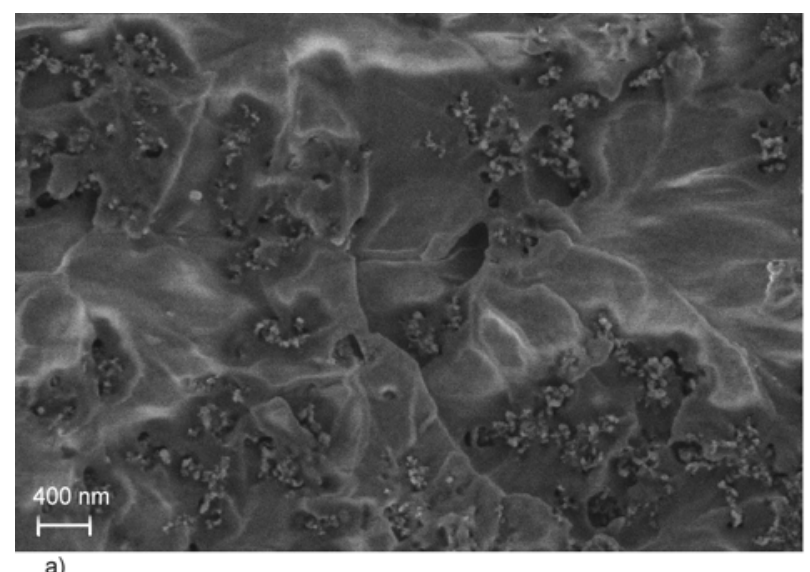

a)

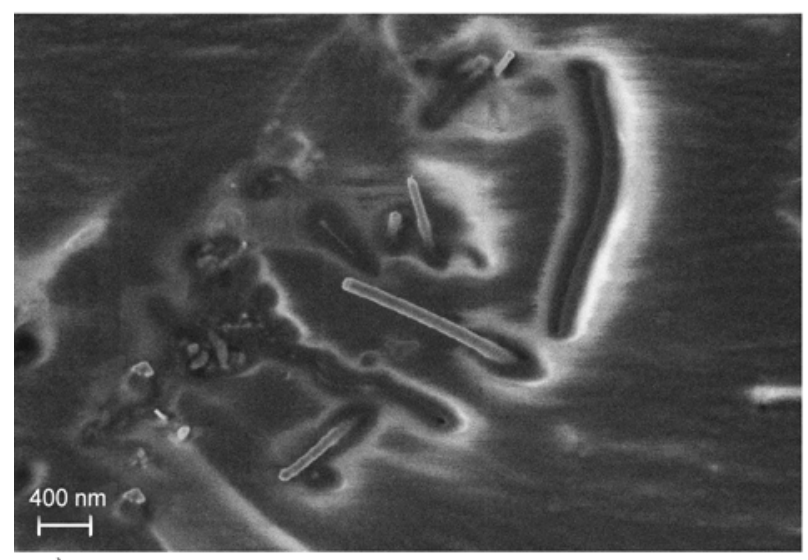

c)

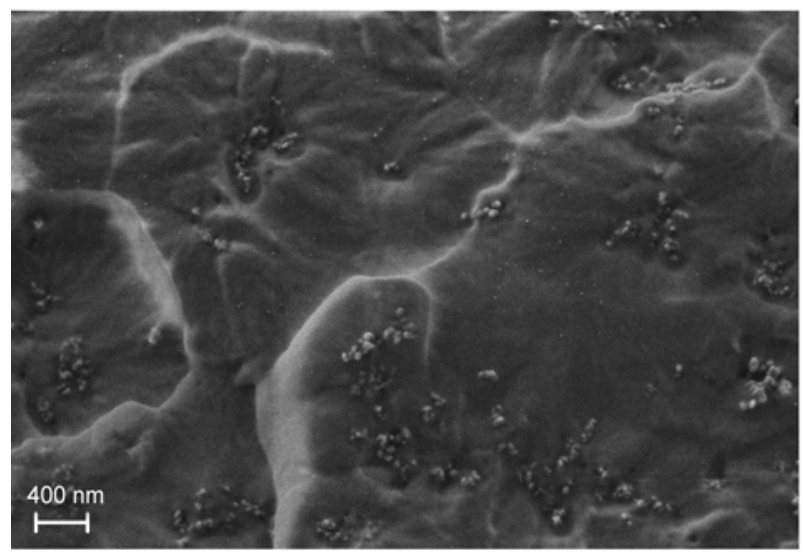

e)

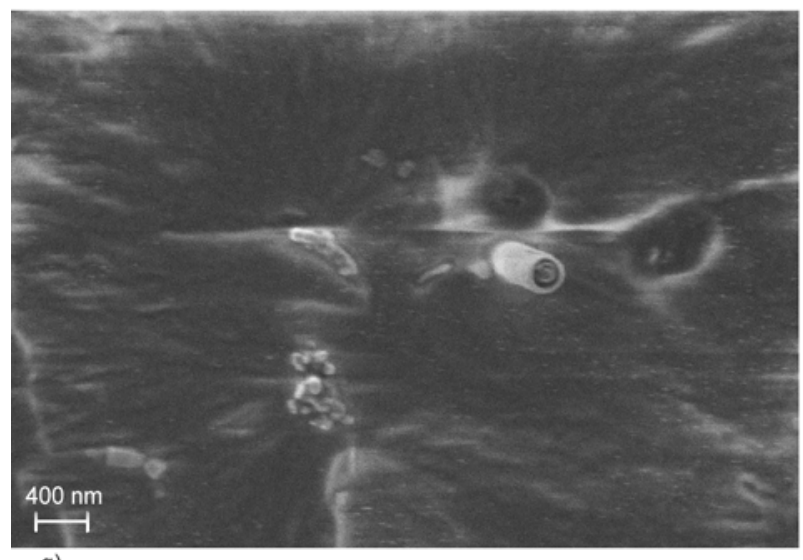

g)

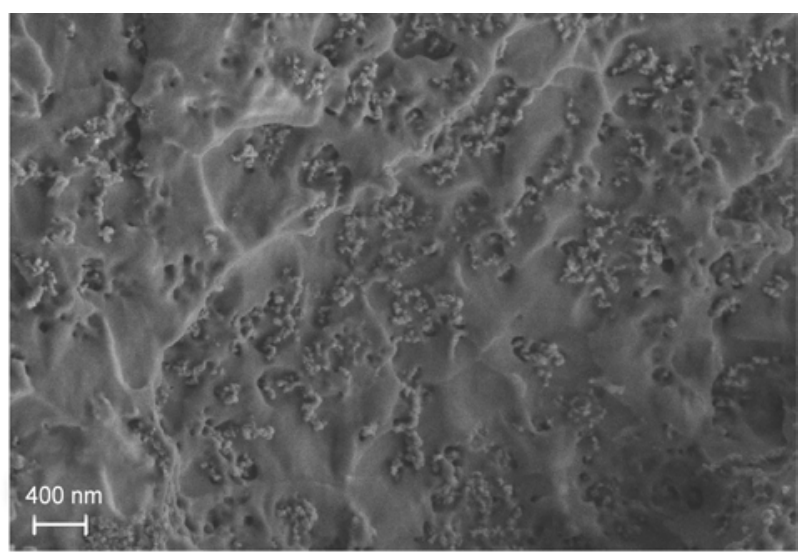

b)

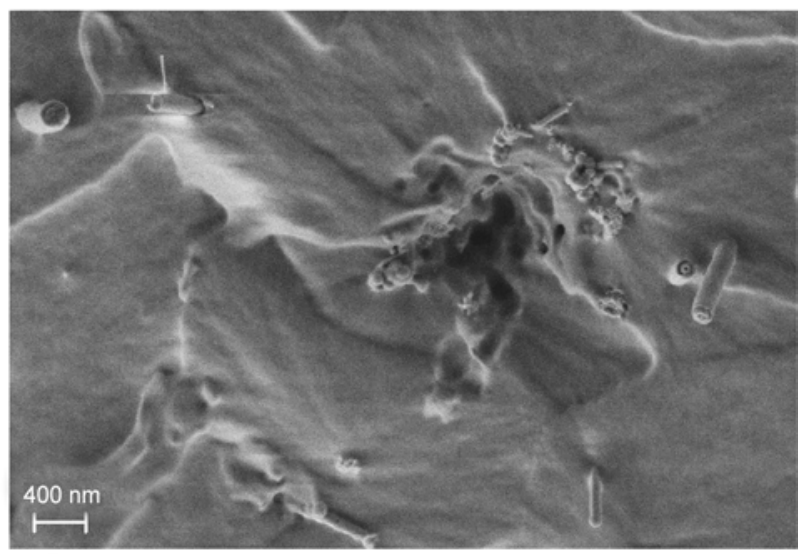

d)
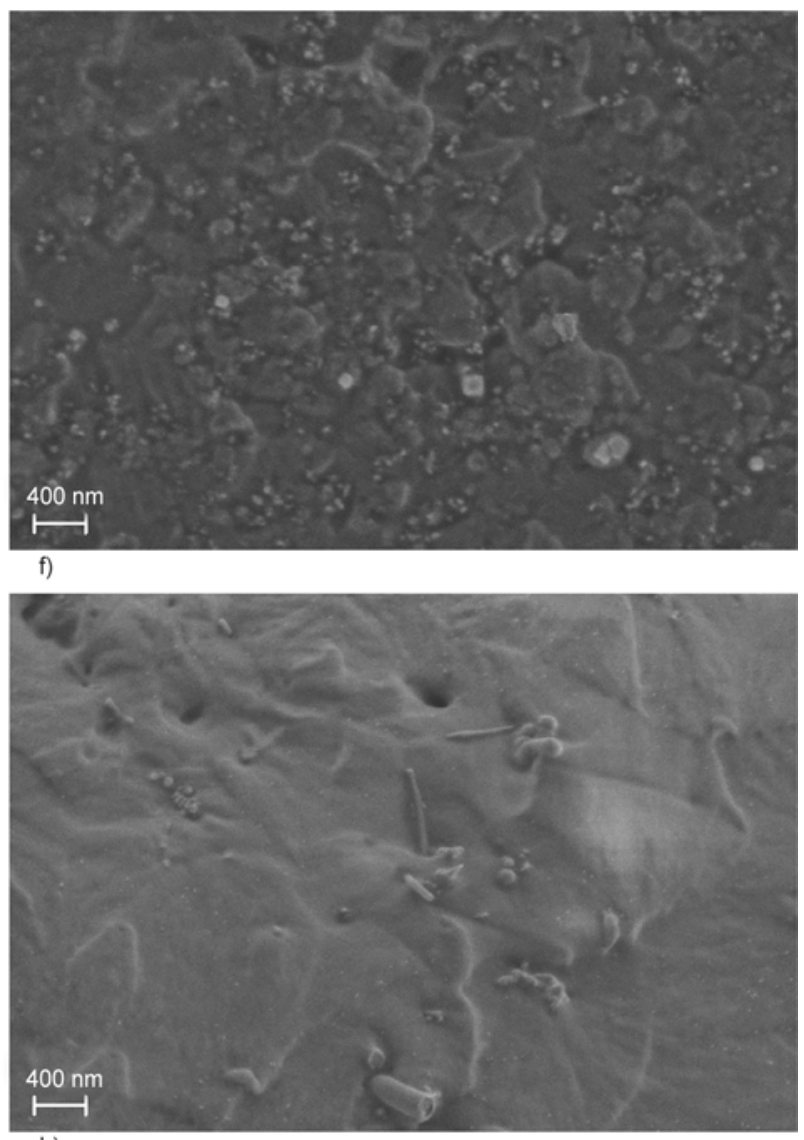

h)

Figure 2. FESEM images of the fracture surfaces of epoxy based nanocomposites: (a) 1CB, (b) 4CB, (c) 1NF, (d) 4NF, (e) $1 \mathrm{CB}+\mathrm{Ag}$, (f) $4 \mathrm{CB}+\mathrm{Ag}$, (g) $1 \mathrm{NF}+\mathrm{Ag}$, (h) $4 \mathrm{NF}+\mathrm{Ag}$ 
average diameter of about $40 \mathrm{~nm}$, organized in agglomerates of about $250 \mathrm{~nm}$ (Figure 2a). 4CB sample manifests a higher particle density and a more pronounced tendency of the particles to form agglomerates (Figure 2b). In fact, the agglomerates are larger (about $450 \mathrm{~nm}$ ) than that detectable at a lower nanofiller content. As often reported for particulate filled nanocomposites, as the filler amount increases the mean interparticle distance diminishes and the probability of aggregation is therefore enhanced [33]. NF filled nanocomposites exhibit a more complex microstructure. Some cavities, most probably related to fiber-matrix debonding phenomena, are detectable on the fracture surface (Figure $2 \mathrm{c}-2 \mathrm{~d}) .1 \mathrm{CB}+\mathrm{Ag}$ and $4 \mathrm{CB}+\mathrm{Ag}$ composites are characterized by a morphology in which silver primary nanoparticles are homogeneously distributed within the matrix forming aggregates of 4-5 nanoparticles having a mean diameter of about $300 \mathrm{~nm}$ (Figure 2e-2f). Interestingly, the microstructure of $1 \mathrm{NF}+\mathrm{Ag}$ and $4 \mathrm{NF}+\mathrm{Ag}$ samples is characterized by the presence of $\mathrm{Ag}$ aggregates localized near the NF or adhering on the nanofiber surface (Figure $2 \mathrm{~g}-2 \mathrm{~h}$ ). This microstructural feature may play an important role in the electrical conductivity.

\subsection{Thermal properties}

Representative DSC thermograms of $\mathrm{EP}$ and $\mathrm{EP}+\mathrm{Ag}$ samples are reported in Figure 3, while $T_{\mathrm{g}}$ values collected during the first heating scan of DSC tests are summarized in Table 1. Comparing $T_{\mathrm{g}}$ data reported in Table 1, it can be concluded that transition temperature seems to be slightly reduced upon nanofiller addition, especially for elevated $\mathrm{CB}$ amounts. A similar trend has been previously

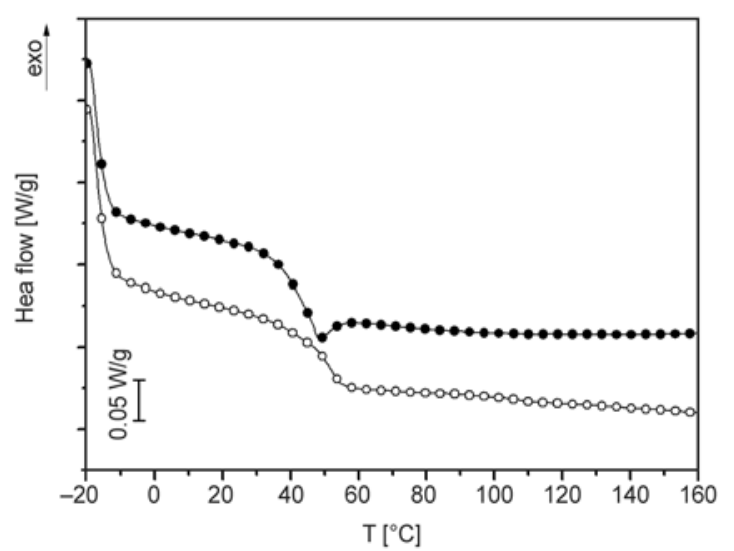

Figure 3. DSC thermograms of EP (०) and EP+Ag (•) samples (first heating stage)
Table 1. Glass transition temperature from DSC tests on neat epoxy and nanocomposites (first heating scan)

\begin{tabular}{|l|c|l|c|}
\hline \multicolumn{1}{|c|}{ Sample } & $\begin{array}{c}\mathbf{T}_{\mathbf{g}} \\
{\left[{ }^{\circ} \mathbf{C}\right]}\end{array}$ & \multicolumn{1}{|c|}{ Sample } & $\begin{array}{c}\mathbf{T}_{\mathbf{g}} \\
{\left[{ }^{\circ} \mathbf{C}\right]}\end{array}$ \\
\hline EP & 49.3 & $\mathrm{EP}+\mathrm{Ag}$ & 47.6 \\
\hline $1 \mathrm{CB}$ & 43.6 & $1 \mathrm{CB}+\mathrm{Ag}$ & 45.5 \\
\hline $2 \mathrm{CB}$ & 46.9 & $2 \mathrm{CB}+\mathrm{Ag}$ & 47.5 \\
\hline $4 \mathrm{CB}$ & 43.0 & $4 \mathrm{CB}+\mathrm{Ag}$ & 42.7 \\
\hline $1 \mathrm{NF}$ & 47.3 & $1 \mathrm{NF}+\mathrm{Ag}$ & 44.1 \\
\hline $2 \mathrm{NF}$ & 46.9 & $2 \mathrm{NF}+\mathrm{Ag}$ & 44.1 \\
\hline $4 \mathrm{NF}$ & 45.3 & $4 \mathrm{NF}+\mathrm{Ag}$ & 45.4 \\
\hline
\end{tabular}

observed and reported by our group for various nanofilled thermosets [6, 33-37], and it can be explained considering that the crosslinking process can be partially hindered for elevated filler loadings. The observed $T_{\mathrm{g}}$ trend could be due to the occurrence of two concurrent phenomena: as the filler content increases the chain blocking effect is more effective and induces a slight $T_{\mathrm{g}}$ increase, while, at the same time, polymer-filler chemical interactions and the viscosity increase reduces the crosslinking degree of the matrix, with a consequent $T_{\mathrm{g}}$ drop. In a recent investigation on epoxy/alumina nanocomposites, Liu et al. [38] speculated that the hardener molecules were unevenly distributed at a microscale, thus leading to a stoichiometric imbalance between epoxy components and reduced $T_{\mathrm{g}}$ values.

\subsection{Mechanical behavior}

Representative load-displacement curves of flexural tests on epoxy based nanocomposites filled with carbon black are reported in Figure 4, while the elastic and yield properties of epoxy/CB and epoxy/NF nanocomposites are respectively reported in Figure 5 and 6 . As it often happens with epoxy

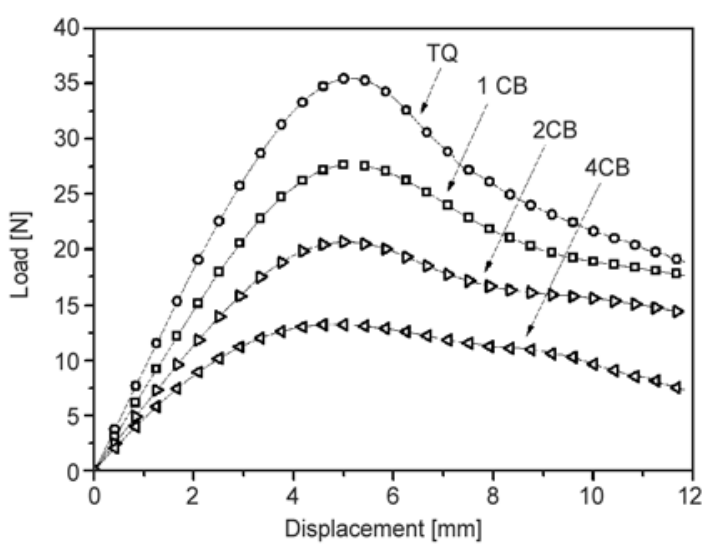

Figure 4. Representative load-displacement curves under flexural conditions for epoxy based nanocomposites filled with carbon black nanoparticles 

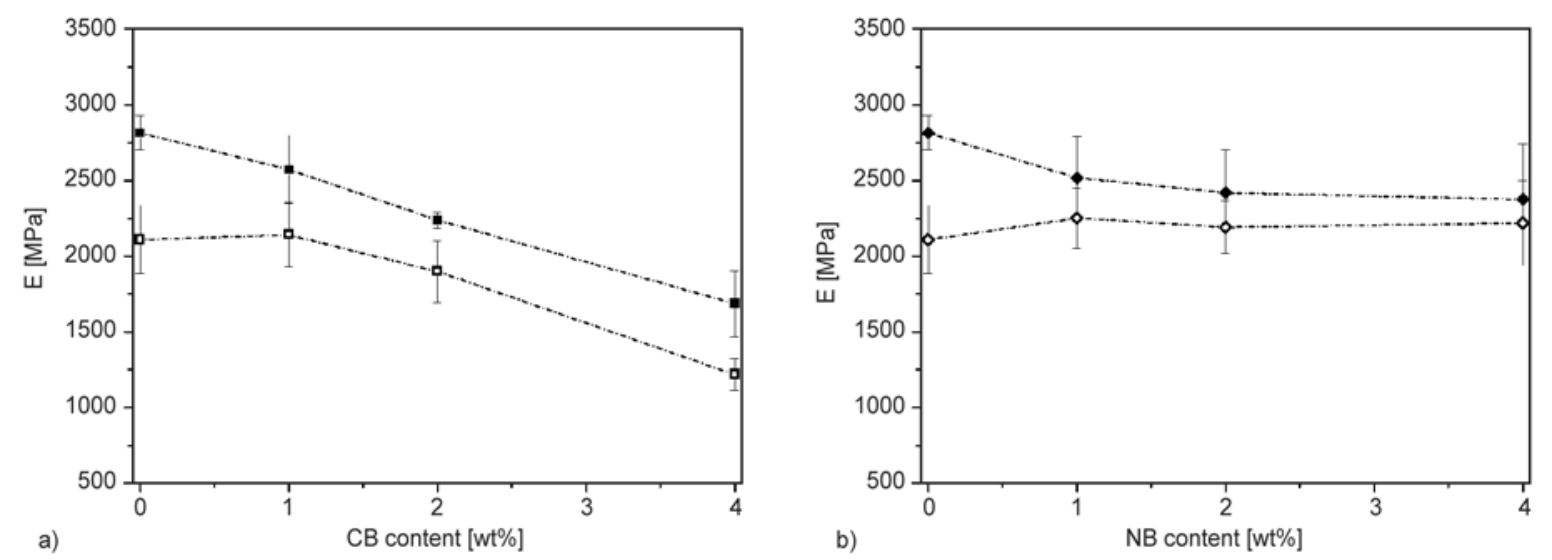

Figure 5. Elastic modulus (E) from flexural tests on: (a) epoxy/CB and on (b) epoxy/NF nanocomposites (nanofiller content $=1-4 \mathrm{wt} \%$ ). Samples with (full symbols) and without (open symbols) Ag nanoparticles.
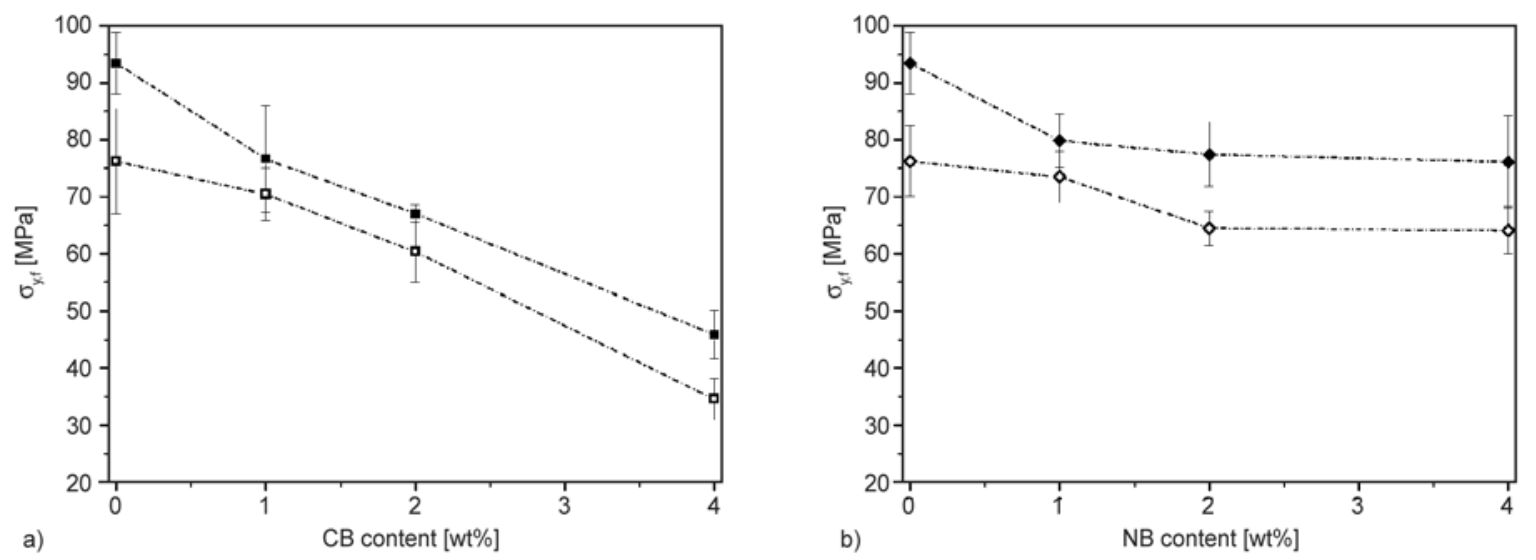

Figure 6. Stress at yield $\left(\sigma_{\mathrm{y}, \mathrm{f}}\right)$ from flexural tests on: (a) epoxy/CB and on (b) epoxy/NF nanocomposites (nanofiller content $=1-4 \mathrm{wt} \%$ ). Samples with (full symbols) and without (open symbols) Ag nanoparticles.

systems with relatively low $T_{\mathrm{g}}$ (around $50^{\circ} \mathrm{C}$ ), the specimens do not break in a brittle manner under flexure, but the load reaches a maximum (i.e. flexural stress at yield), after which a plastic and irreversible deformation process without a clear failure occurs (Figure 4). It can be noticed that the addition of CB markedly plasticizes the epoxy matrix similarly to what previously observed for epoxy/silica nanocomposites [39]. Interestingly, the elastic modulus is reduced by CB introduction (Figure 5a), especially at elevated filler amounts. On the contrary, the elastic modulus seems to be substantially unaffected by NF introduction (Figure 5b). Both this facts and the lower $T_{\mathrm{g}}$ drop detected from DSC tests for NF-based nanocomposites could be explained by considering the lower specific surface area of NF $\left(29 \mathrm{~m}^{2} / \mathrm{g}\right)$ with respect to CB $\left(1353 \mathrm{~m}^{2} / \mathrm{g}\right)$ and, consequently, the different filler/matrix interactions. On the other hand, the introduction of silver nanoparticles systematically increases the stiffness of the composites for all the tested compositions. A similar trend can be observed if the stress at yield values are considered (Figure 6). Flexural yield stress steadily decreases when $\mathrm{CB}$ is added, while $\sigma_{\mathrm{y}, \mathrm{f}}$ is practically constant for NF filled nanocomposites. Even in this case, the introduction of Ag nanoparticles within the hardener enhances the yield resistance of the samples.

\subsection{Electrical conductivity and heating by Joule effect}

In Figure 7a the trend of electrical resistivity of epoxy based nanocomposites without silver nanoparticles are represented, while in Figure $7 \mathrm{~b}$ the electrical resistivity of the corresponding samples with the addition of Ag nanoparticles are summarized. The electrical resistivity of the neat matrix is of about $10^{16} \Omega \cdot \mathrm{cm}$, in the typical range generally reported for epoxy resins [6]. CB filled nanocomposites show a percolation threshold for a filler concentration lower than $1 \mathrm{wt} \%$ (Figure 7a), with a further resistivity drop for higher filler loading, reaching a plateau 

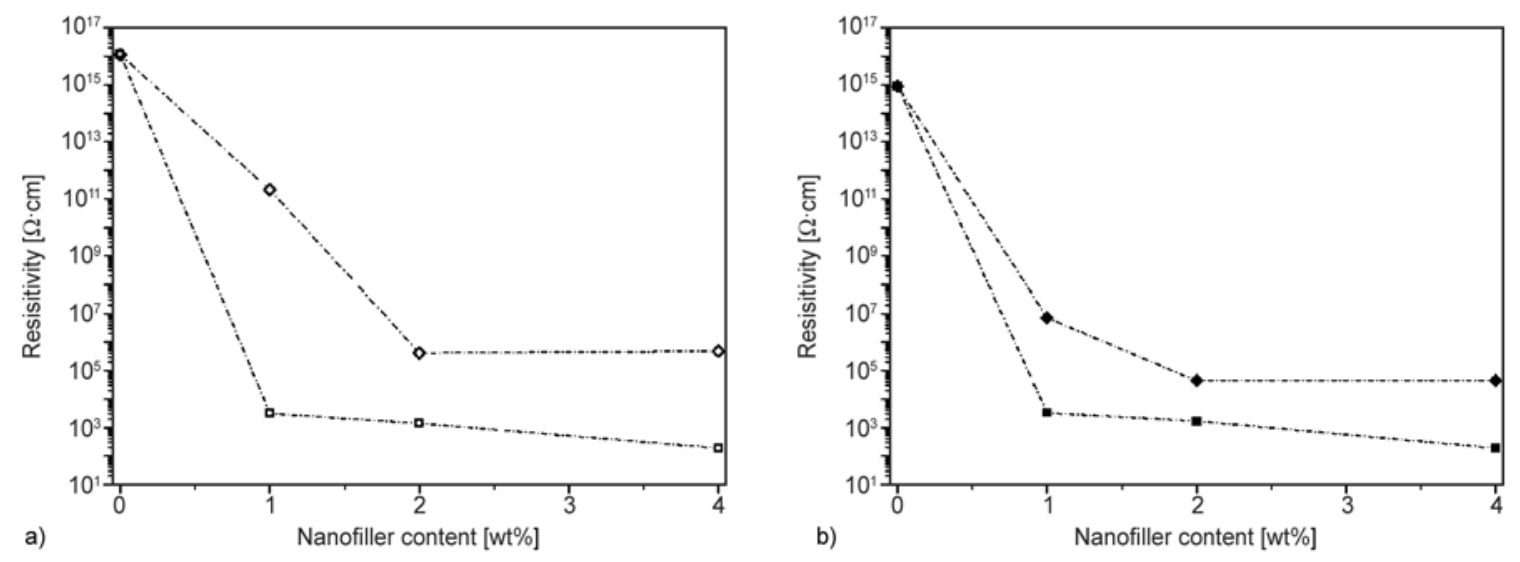

Figure 7. Electrical resistivity of epoxy based nanocomposites (filler content $=1-4 \mathrm{wt} \%$ ). Samples without (a) and with (b) Ag nanoparticles filled with CB $(\square, \boldsymbol{\square})$ or NF $(\diamond, \diamond)$.

value at around $10^{3} \Omega \cdot \mathrm{cm}$ for nanofiller contents of $4 \mathrm{wt} \%$. The electrical resistivity of CB filled nanocomposites is not substantially influenced by the introduction of $\mathrm{Ag}$ nanoparticles. On the other hand, NF based nanocomposites without Ag nanoparticles show a percolation threshold at $2 \mathrm{wt} \%$, reaching a plateau value of $10^{6} \Omega \cdot \mathrm{cm}$ for a filler loading of $4 \mathrm{wt} \%$. It is interesting to observe how the introduction of Ag nanoparticles in NF based nanocompos-
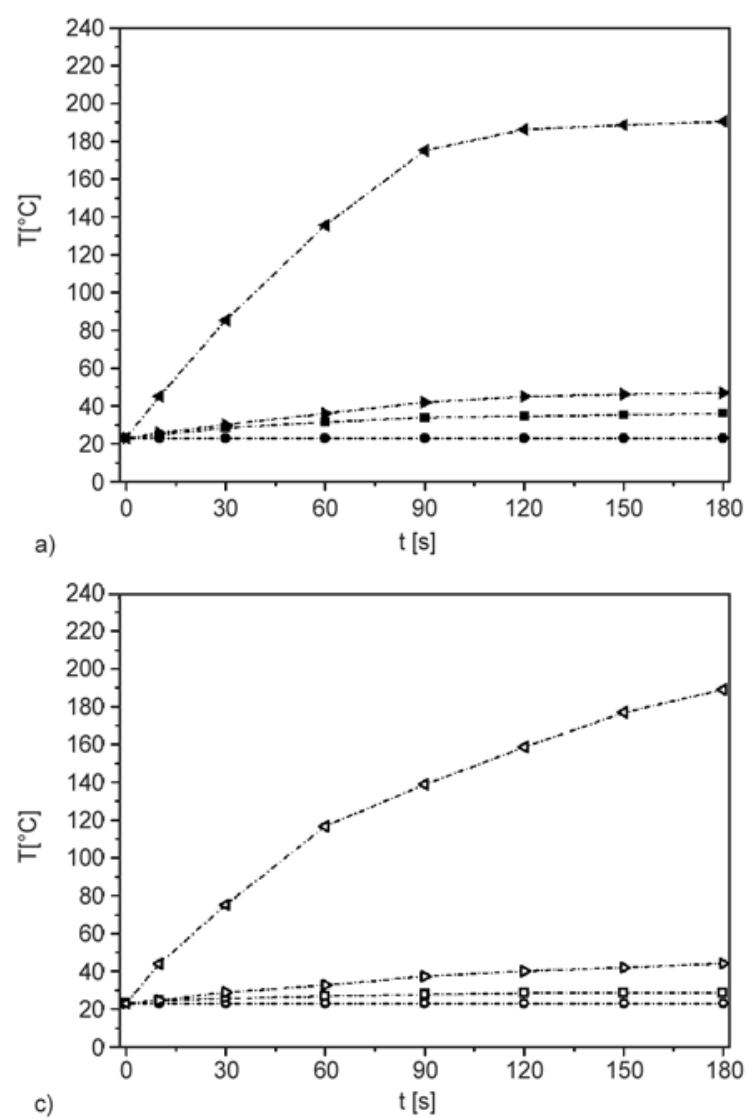

ites leads to a remarkable reduction of electrical resistivity for all the tested compositions, reaching a value of $10^{4} \Omega \cdot \mathrm{cm}$ after the percolation threshold (Figure $7 \mathrm{~b}$ ). The positive contribution played by Ag nanoparticles on the conductivity of these composites can be probably correlated with their peculiar morphological features. As reported in FESEM micrographs (Figure $2 \mathrm{~g}-2 \mathrm{~h}$ ), Ag aggregates are localized near NFs or directly adhere on NFs sur-
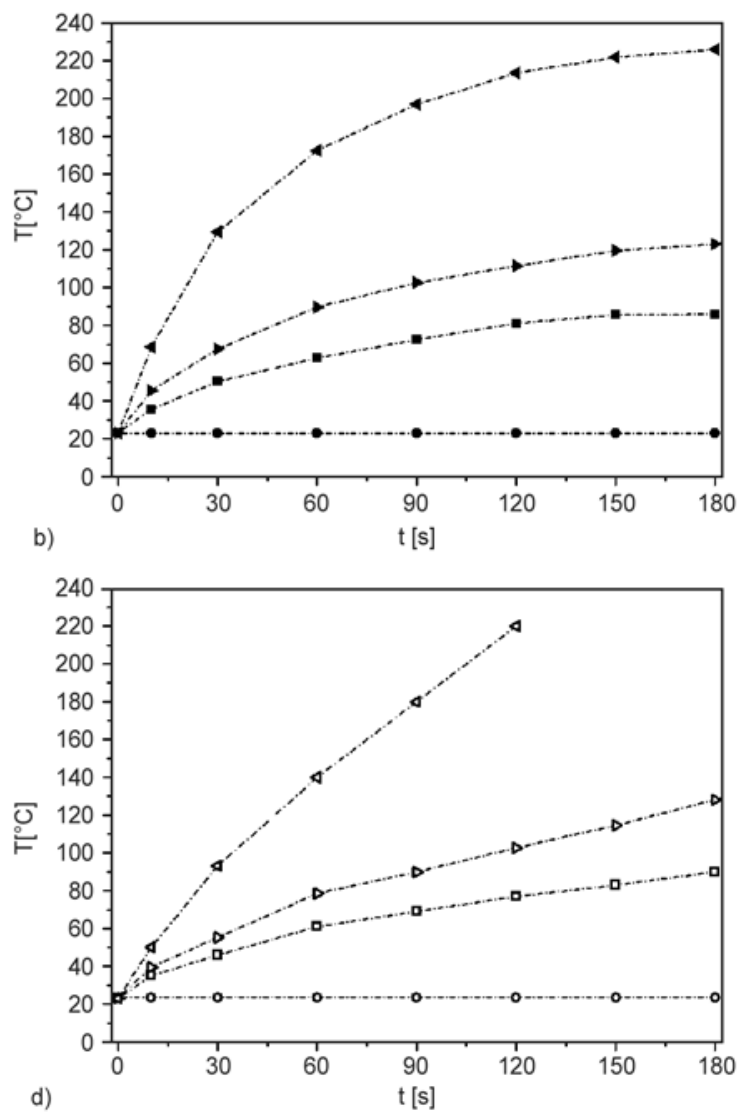

Figure 8. Time dependency of the surface temperature of epoxy/CB nanocomposites at an applied voltage of (a-c) $100 \mathrm{~V}$ and (b-d) 220 V. CB content of $0 \mathrm{wt} \%(\bullet, \circ), 1 \mathrm{wt} \%(\boldsymbol{\bullet}, \square), 2 \mathrm{wt} \%(\bullet, \triangleright)$ and $4 \mathrm{wt} \%(\triangleleft, \triangleleft)$. Samples with (full symbols) and without (open symbols) Ag nanoparticles. 
face. In these conditions the formation of a conductive path is favored, with a consequent reduction of the electrical resistivity.

Considering that the eventual application of the tested materials as electro active SMPs is strictly connected to their capability of reaching the transition temperature (i.e. the glass transition temperature for epoxy systems) upon voltage application, surface temperature measurements at different voltages were performed. In Figure $8 \mathrm{a}-8 \mathrm{~d}$ the time dependency of the surface temperature of epoxy/CB nanocomposites is summarized. Except for the samples without $\mathrm{CB}$ and NF, it can be noticed that the surface temperature increases with the voltage application time. Moreover, for all the tested specimens the surface temperature increases proportionally to the nanofiller amount in the whole interval of voltage application time. At $100 \mathrm{~V}$, the transition temperature (about $45^{\circ} \mathrm{C}$ ) can be reached only with a $\mathrm{CB}$ content of $4 \mathrm{wt} \%$ (Figure $8 \mathrm{a}-8 \mathrm{c}$ ). Increasing the voltage up to $220 \mathrm{~V}$, all samples reach a temperature higher than $45^{\circ} \mathrm{C}\left(T_{\mathrm{g}}\right)$ in less than $30 \mathrm{~s}$ (Figure $8 \mathrm{~b}-$ 8d). Interestingly, the presence of Ag nanoparticles
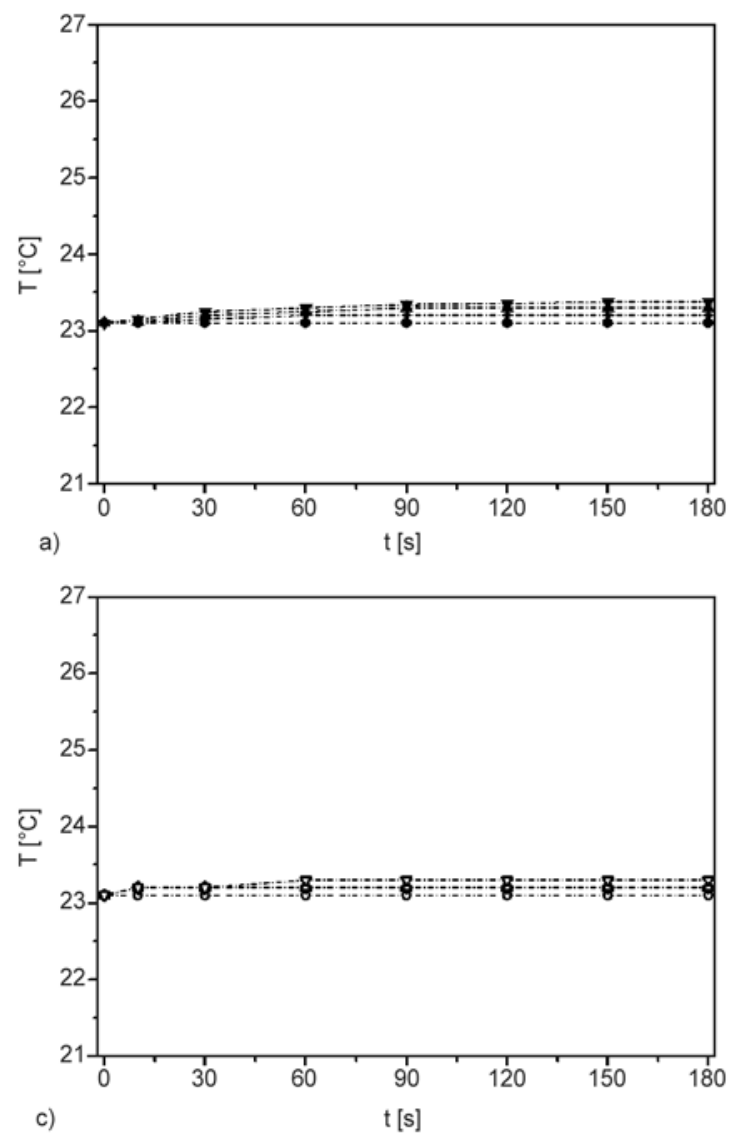

within the matrix is able to stabilize the temperature reached by the samples for long voltage application times (Figure 8a-8b). This feature is probably related to the high heat dissipation capability of Ag nanoparticles within the matrix. Considering that the electrical conductivity of CB nanocomposites is not substantially affected by the presence of silver within the matrix, this peculiar feature can be related to the higher heat dissipation capability of the composites in the presence of metallic nanoparticles. This aspect is very important to prevent the overheating and the consequent thermal degradation of the material at elevated voltages. The same tests were performed on NF filled nanocomposites and the most important results are summarized in Figure 9a-9d. Regardless the presence of $\mathrm{Ag}$ nanoparticles, an applied voltage of $100 \mathrm{~V}$ is not enough to raise the surface temperature up to the $T_{\mathrm{g}}$ of the material (Figure $9 \mathrm{a}-$ $9 \mathrm{c})$. The increase of the voltage up to $220 \mathrm{~V}$ promotes a slight heating of the samples increasing with the NF amount. However, the temperature of $26^{\circ} \mathrm{C}$ reached on the surface of $4 \mathrm{wt} \%$ filled nanocomposites after $180 \mathrm{~s}$ is by far below the glass tran-
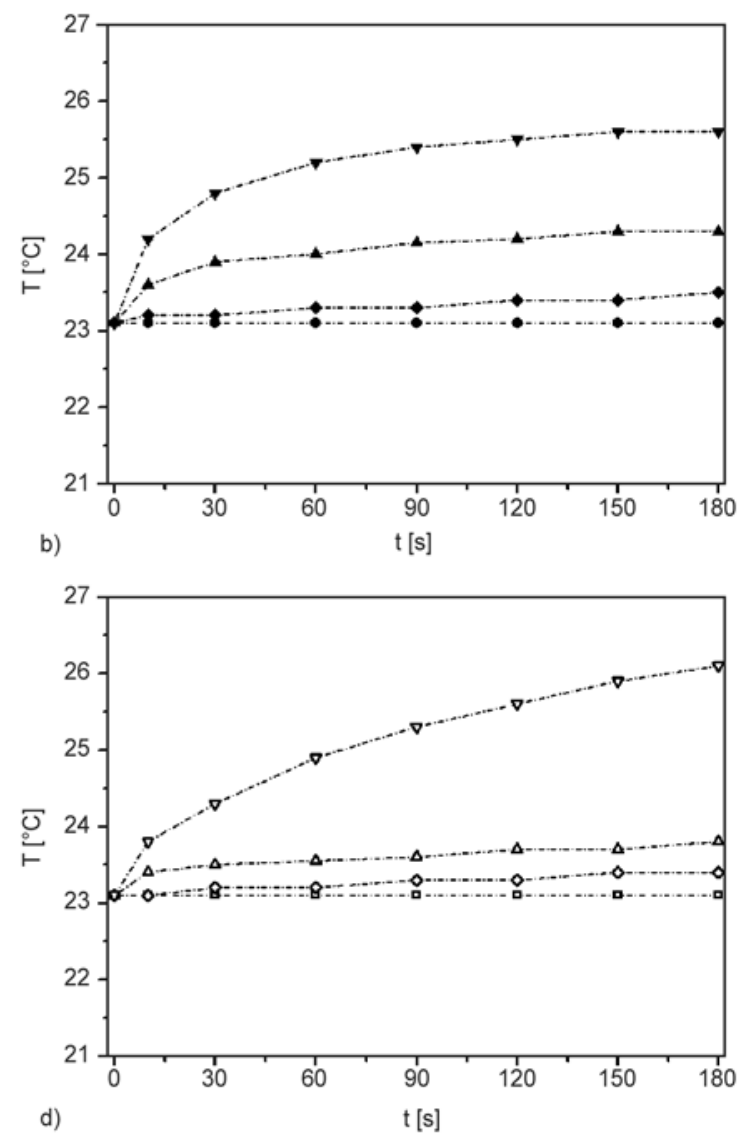

Figure 9. Time dependency of the surface temperature of epoxy/NF nanocomposites at an applied voltage of (a-c) $100 \mathrm{~V}$ and (b-d) $220 \mathrm{~V}$. NF content of $0 \mathrm{wt} \%(\bullet, \circ), 1 \mathrm{wt} \%(\bullet, \diamond), 2 \mathrm{wt} \%(\bullet, \triangle)$ and $4 \mathrm{wt} \%(\nabla, \nabla)$. Samples with (full symbols) and without (open symbols) Ag nanoparticles. 
sition temperature of the material (Figure 9b-9d). On the other hand, electrical resistivity measurements (Figure 7a-7b) demonstrated how the conductivity of CB nanocomposites is systematically higher than that of the corresponding NF filled samples. This means that an electrical resistivity of about $10^{3} \Omega \cdot \mathrm{cm}$ is required to thermally activate epoxy based nanocomposites by Joule effect, and that the presence of high heat dissipating filler (i.e. Ag nanoparticles) promotes temperature stabilization for long voltage application times.

\section{Conclusions}

Conductive polymer nanocomposites were prepared adding different amounts of carbon black and carbon nanofibers to an epoxy resin nanomodified with in-situ generated silver nanoparticles. The glass transition temperature of the material was slightly decreased by the addition of both $\mathrm{CB}$ and $\mathrm{NF}$, while the dimension of $\mathrm{CB}$ aggregates within the matrix increased with the filler content. The introduction of $\mathrm{CB}$ promoted a decrease of the stiffness and of the yield properties of the matrix, while $\mathrm{Ag}$ nanoparticles were responsible of an interesting improvement of the flexural yield stress. The electrical resistivity of the materials was strongly reduced upon $\mathrm{CB}$ introduction, with a percolation threshold of about $1 \mathrm{wt} \%$. Surface temperature of CB nanocomposites was rapidly increased above the glass transition temperature when a proper voltage was applied. Ag nanoparticles resulted to be effective in stabilizing the temperature for elevated voltage application times, thus avoiding the thermal degradation of the material.

\section{References}

[1] Liu C., Qin H., Mather P. T.: Review of progress in shape-memory polymers. Journal of Materials Chemistry, 17, 1543-1558 (2007).

DOI: 10.1039/B615954K

[2] Fan Z., Zheng C., Wei T., Zhang Y., Luo G.: Effect of carbon black on electrical property of graphite nanoplatelets/epoxy resin composites. Polymer Engineering and Science, 49, 2041-2045 (2009).

DOI: $10.1002 /$ pen.21445

[3] Li J., Wong P-S., Kim J-K.: Hybrid nanocomposites containing carbon nanotubes and graphite nanoplatelets. Materials Science and Engineering A, 483484, 660-663 (2008).

DOI: $10.1016 /$ j.msea.2006.08.145
[4] Sumfleth J., Buschhorn S. T., Schulte K.: Comparison of rheological and electrical percolation phenomena in carbon black and carbon nanotube filled epoxy polymers. Journal of Materials Science, 46, 659-669 (2011). DOI: $10.1007 / \mathrm{s} 10853-010-4788-6$

[5] Traina M., Pegoretti A., Penati A.: Time-temperature dependence of the electrical resistivity of high-density polyethylene/carbon black composites. Journal of Applied Polymer Science, 106, 2065-2074 (2007). DOI: $10.1002 /$ app.26444

[6] Pedrazzoli D., Dorigato A., Pegoretti A.: Monitoring the mechanical behaviour of electrically conductive polymer nanocomposites under ramp and creep conditions. Journal of Nanoscience and Nanotechnology, 12, 4093-4102 (2012).

DOI: $10.1166 /$ jnn.2012.6219

[7] Pedrazzoli D., Dorigato A., Pegoretti A.: Monitoring the mechanical behavior under ramp and creep conditions of electrically conductive polymer composites. Composites Part A: Applied Science and Manufacturing, 43, 1285-1292 (2012).

DOI: $10.1016 /$ j.compositesa.2012.03.019

[8] Lendlein A., Kelch S.: Shape-memory polymers. Angewandte Chemie International Edition, 41, 20342057 (2002).

DOI: 10.1002/1521-3773(20020617)41:12<2034::AIDANIE2034>3.0.CO;2-M

[9] Bogue R.: Shape-memory materials: A review of technology and applications. Assembly Automation, 29, 214-219 (2009).

DOI: $10.1108 / 01445150910972895$

[10] Sun L., Huang W. M., Ding Z., Zhao Y., Wang C. C., Purnawali H., Tang C.: Stimulus-responsive shape memory materials: A review. Materials and Design, 33, 577-640 (2012).

DOI: $10.1016 /$ j.matdes.2011.04.065

[11] Meng Q., Hu J., Zhu Y., Lu J., Liu Y.: Morphology, phase separation, thermal and mechanical property differences of shape memory fibres prepared by different spinning methods. Smart Materials and Structures, 16, 1192-1197 (2007). DOI: 10.1088/0964-1726/16/4/030

[12] Metcalfe A., Desfaits A-C., Salazkin I., Yahia L., Sokolowski W. M., Raymond J.: Cold hibernated elastic memory foams for endovascular interventions. Biomaterials, 24, 491-497 (2003). DOI: $10.1016 / \mathrm{S} 0142-9612(02) 00362-9$

[13] Charlesby A.: Atomic radiation and polymers.Pergamon Press, New York (1960).

[14] Mondal S., Hu J. L., Yong Z.: Free volume and water vapor permeability of dense segmented polyurethane membrane. Journal of Membrane Science, 280, 427432 (2006).

DOI: $10.1016 /$ j.memsci.2006.01.047

[15] Kim B. K., Lee S. Y., Xu M.: Polyurethanes having shape memory effects. Polymer, 37, 5781-5793 (1996). DOI: $10.1016 / \mathrm{S} 0032-3861(96) 00442-9$ 
[16] Gall K., Dunn M. L., Liu Y., Finch D., Lake M., Munshi N. A.: Shape memory polymer nanocomposites. Acta Materialia, 50, 5115-5126 (2002). DOI: $10.1016 / \mathrm{S} 1359-6454(02) 00368-3$

[17] Hu J. L., Ji F. L., Wong Y. W.: Dependency of the shape memory properties of a polyurethane upon thermomechanical cyclic conditions. Polymer International, 54, 600-605 (2005).

DOI: $10.1002 /$ pi. 1745

[18] Wang C. C., Huang W. M., Ding Z., Zhao Y., Purnawali H.: Cooling-/water-responsive shape memory hybrids. Composites Science and Technology, 72, 11781182 (2012). DOI: 10.1016/j.compscitech.2012.03.027

[19] Lendlein A., Jiang H., Jünger O., Langer R.: Lightinduced shape-memory polymers. Nature, 434, 879882 (2005).

DOI: 10.1038 /nature03496

[20] Jiang H., Kelch S., Lendlein A.: Polymers move in response to light. Advanced Materials, 18, 1471-1475 (2006).

DOI: $10.1002 / \mathrm{adma} .200502266$

[21] Cho J. W., Kim J. W., Jung Y. C., Goo N. S.: Electroactive shape-memory polyurethane composites incorporating carbon nanotubes. Macromolecular Rapid Communication, 26, 412-416 (2005).

DOI: $10.1002 /$ marc. 200400492

[22] Paik I. H., Goo N. S., Jung Y. C., Cho J. W.: Development and application of conducting shape memory polyurethane actuators. Smart Materials and Structures, 15, 1476-1482 (2006).

DOI: $10.1088 / 0964-1726 / 15 / 5 / 037$

[23] Yang B., Huang W. M., Li C., Li L., Chor J. H.: Qualitative separation of the effects of carbon nano-powder and moisture on the glass transition temperature of polyurethane shape memory polymer. Scripta Materialia, 53, 105-107 (2005).

DOI: 10.1016/j.scriptamat.2005.03.009

[24] Leng J., Lv H., Liu Y., Du S.: Electroactivate shapememory polymer filled with nanocarbon particles and short carbon fibers. Applied Physics Letters, 91, 144105/1-144105/3 (2007).

DOI: $10.1063 / 1.2790497$

[25] Schmidt A. M.: Electromagnetic activation of shape memory polymer networks containing magnetic nanoparticles. Macromolecular Rapid Communication, 27, 1168-1172 (2006).

DOI: $10.1002 /$ marc. 200600225

[26] Koerner H., Price G., Pearce N., Alexander M., Vaia R. A.: Remotely actuated polymer nanocomposites-stressrecovery of carbon-nanotube-filled thermoplastic elastomers. Nature Materials, 3, 115-120 (2004).

DOI: $10.1038 /$ nmat1059

[27] Leng J. S., Lan X., Liu Y. J., Du S. Y., Huang W. M., Liu N., Phee S. J., Yuan Q.: Electrical conductivity of thermoresponsive shape-memory polymer with embedded micron sized Ni powder chains. Applied Physics Letters, 92, 014104/1-014104/3 (2008).

DOI: $10.1063 / 1.2829388$
[28] Leng J. S., Huang W. M., Lan X., Liu Y. J., Du S. Y.: Significantly reducing electrical resistivity by forming conductive Ni chains in a polyurethane shape-memory polymer/carbon-black composite. Applied Physics Letters, 92, 204101/1-204101/3 (2008).

DOI: $10.1063 / 1.2931049$

[29] Narendra Kumar U., Kratz K., Behl M., Lendlein A.: Shape-memory properties of magnetically active tripleshape nanocomposites based on a grafted polymer network with two crystallizable switching segments. Express Polymer Letters, 6, 26-40 (2012).

DOI: 10.3144/expresspolymlett.2012.4

[30] Fan K., Huang W. M., Wang C. C., Ding Z., Zhao Y., Purnawali H., Liew K. C., Zheng L. X.: Water-responsive shape memory hybrid: Design concept and demonstration. Express Polymer Letters, 5, 409-416 (2011). DOI: $10.3144 /$ expresspolymlett.2011.40

[31] Behl M., Lendlein A.: Shape-memory polymers. Materials Today, 10, 20-28 (2007).

DOI: $10.1016 / \mathrm{S} 1369-7021(07) 70047-0$

[32] Yong Y., Matsubara S., Xiong L., Hayakawa T., Nogami M.: Solvothermal synthesis of multiple shapes of silver nanoparticles and their SERS properties. Journal of Physical Chemistry C, 111, 9095-9104 (2007). DOI: $10.1021 / j p 068859 b$

[33] Dorigato A., D'Amato M., Pegoretti A.: Thermomechanical properties of high density polyethylene fumed silica nanocomposites: Effect of filler surface area and treatment. Journal of Polymer Research, 19, 9889/1-9889/11 (2012).

DOI: $10.1007 / \mathrm{s} 10965-012-9889-2$

[34] Dorigato A., Pegoretti A.: The role of alumina nanoparticles in epoxy adhesives. Journal of Nanoparticle Research, 13, 2429-2441 (2011).

DOI: $10.1007 / \mathrm{s} 11051-010-0130-0$

[35] Dorigato A., Pegoretti A. P., Penati A.: Effect of the polymer-filler interaction on the thermo-mechanical response of polyurethane-clay nanocomposites from blocked prepolymer. Journal of Reinforced Plastics and Composites, 30, 325-335 (2011).

DOI: $10.1177 / 0731684410396599$

[36] Dorigato A., Pegoretti A., Bondioli F., Messori M.: Improving epoxy adhesives with zirconia nanoparticles. Composite Interfaces, 17, 873-892 (2010). DOI: $10.1163 / 092764410 X 539253$

[37] Pegoretti A., Dorigato A., Brugnara M., Penati A.: Contact angle measurements as a tool to investigate the filler-matrix interactions in polyurethane-clay nanocomposites from blocked prepolymer. European Polymer Journal, 44, 1662-1672 (2008).

DOI: $10.1016 /$ j.eurpolymj.2008.04.011

[38] Liu G., Zhang H., Zhang D-J., Zhang H., Zhang Z., An X-F., Yi X-S.: On depression of glass transition temperature of epoxy nanocomposites. Journal of Materials Science, 47, 6891-6895 (2012). DOI: $10.1007 / \mathrm{s} 10853-012-6633-6$

[39] Preghenella M., Pegoretti A., Migliaresi C.: Thermomechanical characterization of fumed silica-epoxy nanocomposites. Polymer, 46, 12065-12072 (2005). DOI: $10.1016 /$ j.polymer.2005.10.098 